\title{
PRODUÇÃO DE CELULASES E XILANASE POR Aspergillus niger IZ-9 USANDO FERMENTAÇÃO SUBMERSA SOBRE BAGAÇO DE CANA- DE-AÇÚCAR
}

\author{
CLAUDIO LIMA AGUIAR * \\ TOBIAS J. B. MENEZES **
}

\begin{abstract}
Avaliou-se a produção de celulases e xilanase de Aspergillus niger IZ-9, crescido sobre bagaço de cana, quimicamente tratado, como substrato. Os tratamentos foram: solução de hidróxido de sódio a $4 \%$, e solução de hidróxido de sódio a $4 \%$, ácido fosfórico p.a. e vapor. A produção das enzimas celulolíticas (celulase total, endoglicanase e $\beta$ glicosidase) e xilanase foi observada nos bagaços tratados e não-tratado. O tratamento com solução de hidróxido de sódio a $4 \%$ promoveu maior indução de síntese da maioria das enzimas, com exceção de $\beta$-glicosidase, a qual apresentou produção semelhante para os bagaços tratados quimicamente.
\end{abstract}

\section{INTRODUÇÃO}

Os fungos são os mais importantes microrganismos utilizados pela indústria na produção de enzimas (NOVO NORDISK, 1996; MENEZES, 1997) e os principais celulolíticos produtores de celulases e xilanase incluem: Trichoderma reesei (também denominado Trichoderma viride), Trichoderma koningii, Trichoderma lignorum, Sporotrichum pulverulentum (também denominado Chrysosporum lignorum), Penicillium funiculosum, Penicillium iriensis, Aspergillus $\mathrm{sp}$, Schizophyllumm sp, Chaetomium $\mathrm{sp}$ (BISARIA \& GHOSE, 1981) e Humicola sp (DA SILVA et al., 1994). As xilanases, principais hemicelulases estudadas, são encontradas em várias bactérias, tais como as dos gêneros Bacillus sp, Bacteroides sp, Ruminococcus sp, Clostridium sp (BISARIA \& GHOSE, 1984) e em fungos dos gêneros Myrothecium sp, Humicola sp e Penicillium sp (DA SILVA et al., 1994). Algumas leveduras como as do gênero Trichosporium sp também são produtoras de xilanases e celulases, assim como diversas espécies de Aspergillus produzem altos níveis de $\beta$-glicosidase (STEVENS \& PAYNE, 1977).

* M.Sc., Professor, Universidade Estadual de Campinas, Departamento de Ciência de Alimentos, Laboratório de Bioquímica, Campinas, SP (claguiar@yahoo.com.br).

** Professor, Dr., Escola Superior de Agricultura Luiz de Queiroz, USP, Departamento de Agroindústria, Alimentos e Nutrição, Setor de Açúcar e Álcool, SP 
Aspergillus niger é fonte de celulase destinada ao uso alimentício e Trichoderma viride é usado para aplicações não alimentícias, embora ambas enzimas possam cumprir muitas tarefas. Suas enzimas são concentradas e parcialmente purificadas antes de serem comercializadas (BIGELIS, 1993). Segundo GOKHALE (1986) Aspergillus niger pode ser considerado, algumas vezes, superior aos outros fungos, reconhecidamente bons produtores dos complexos celulolíticos e hemicelulolíticos, como Trichoderma viride.

Diversos substratos são utilizados com o objetivo de se obter grandes quantidades de enzimas celulolíticas por microrganismos (VITTI, 1988; SILVA \& DILLON, 1988). Os resíduos agrícolas podem ser devidamente moídos ou triturados para servir como fonte de nutrientes, principalmente de carbono, em fermentação submersa (DA SILVA et al., 1994). Na maioria dos casos, o simples enriquecimento destes compostos com fonte de nitrogênio, minerais ou vitaminas é suficiente para produção de elevada atividade enzimática (BISARIA \& GHOSE, 1981; ELISASHVILI, 1993).

Segundo LOWE et al. (1987) atividades celulolíticas e xilanolíticas, com Neocallimastix frontalis, têm sido obtidas in vitro, utilizando-se papel de filtro e celulose microcristalina como substrato. TRIVEDI \& RAO, citados por VITTI (1988), observaram que açúcares como glicose, sacarose, maltose e arabinose não induziram a formação de celulase total por Aspergillus fumigatus. Altos níveis da enzima celulolítica foram observados quando celulose insolúvel foi usada como fonte de carbono. JOGLEKAR \& KARANTH, citados por VITTI (1988), verificaram que o desenvolvimento de Penicillium funiculosum UV-49 em algodão, papel de filtro, bagaço de cana e carboximetil celulose foi pequeno e a atividade celulolítica baixa. Porém DEKKER, citado por VITTI (1988), observou que as celuloses que não são facilmente hidrolisadas pelas celulases, como Avicel, algodão, celulose em pó e carboximetil celulose parecem ser os melhores substratos para induzir a formação de celulase. GONG \& TSAO (1975) observaram que indutores da síntese de celulases incluem celulose, derivados de celulose, celobiose, soforose e lactose.

A resposta das células fúngicas aos diferentes indutores varia dependendo da concentração e tipo do indutor, ou pela presença de glicose ou outros açúcares no meio de crescimento. Os indutores da síntese de celulolítica têm duas funções, ou seja, podem servir como fonte de carbono para o crescimento celular, ou mesmo como indutores da síntese enzimática (GONG \& TSAO, 1975).

Segundo MENEZES et al. (1976) a atividade celulolítica de linhagens fúngicas, como Aspergillus niger, desenvolvidas em bagaço de cana foi superior às cultivadas em carboximetil celulose e papel de filtro. Sugeriram que estas linhagens produzem a fração exoglicanase, uma vez que o bagaço é uma celulose in natura e não havia recebido qualquer tratamento 
químico, o que exigiria ação da fração pré-hidrolítica da exoglicanase antes de ser hidrolisada pelas outras frações endoglicanase e $\beta$-glicosidase.

MENEZES et al. (1991) obtiveram valores próximos a $0,25 \mathrm{Ul} / \mathrm{mL}$ de celulase total de Aspergillus niger, quando utilizaram bagaço de cana prétratado com solução de hidróxido de sódio 4\%, como fonte de carbono.

COSTA et al. (1997) utilizaram substratos alternativos de baixo custo, ou seja, soja, milho e arroz na produção de enzimas, porém estes substratos não produziram resultados satisfatórios na produção de celulase de $A$. oryzae IMI.

Resíduos lignocelulósicos disponíveis em abundância podem ser excelentes substratos para a produção enzimática por fermentação em estado sólido. Cultura mista de Aspergillus ellipticus e Aspergillus fumigatus desenvolvida em bagaço de cana pré-tratado com solução de hidróxido de cálcio a $2 \%$ foi favorável à produção de celulase e $\beta$ glicosidase, após 8 dias de fermentação (GUPTA \& MADAMWAR, 1997). ABD-EL-NASSER et al. (1997) testaram três fungos: Phanerochaete chrysosporium NRRL 6359, Phanerochaete chrysosporium NRRL 6361 e Coriolus versicolor NRRL 6102, quanto às suas capacidades de produzir xilanase e celulase, em resíduos agrícolas (bagaço de cana tratado e nãotratado, palha de trigo, espigas de milho, cascas de arroz e celulose em pó). Espigas de milho, palha de trigo e bagaço de cana tratado promoveram maior indução enzimática.

A partir de Thermoascus aurantiacus, um fungo termófilo, foram obtidas por fermentação submersa em meio à base de hidrolisado hemicelulósico de bagaço de cana, atividades enzimáticas de 4,2, 3,3, $98 \mathrm{Ul} / \mathrm{mL}$ para endoglicanase, exoglicanase e xilanase, respectivamente (MILAGRES et al., 1994).

Segundo UMIKALSON et al. (1997) uma linhagem de Chaetomium globosum apresentou bom crescimento e substancial quantidade de celulase em fibras deslignificadas de palma, produzindo extrato celulolítico cujas atividades de celulase total, endoglicanase e $\beta$-glicosidase foram 1,4 , 30,8 e $9,8 \mathrm{UI} / \mathrm{mL}$, respectivamente.

Para VLAEV et al. (1997) a máxima produção de celulase total foi percebida com 72 horas de fermentação e de xilanase com 96 horas, obtendo-se menor atividade em fibras de sabugo de milho do que em Avicel, possivelmente, devido à presença de inibidores. A atividade de xilanase na fibra de espiga de milho alcançou $70-80 \%$ do valor obtido com Avicel e a atividade de celulase total alcançou somente $30 \%$ de valor medido com Avicel, possivelmente, devido ao maior teor de lignina naquele substrato. 
Atividades enzimáticas de $0,4,2,5,3,5$ e $0,14 \mathrm{U} / \mathrm{mL}$ de celulase total, endoglicanase, xilanase e $\beta$-xilosidase, respectivamente, foram obtidas por Aspergillus fumigatus crescido sobre resíduos de grama (Leptochloa fusca), enquanto Sporotrichum thermophile produziu $0,47 \mathrm{U} / \mathrm{mL}$ de $\beta$ glicosidase. Chaetomium thermophile, Humicola grisea e Torula thermophila tiveram baixas atividades enzimáticas sobre este substrato. Dentre vários substratos lignocelulósicos, a grama foi comparável à palha de trigo ou de arroz e foi ainda melhor que bagaço de cana in natura para produção enzimática (LATIF et al., 1995).

Segundo RAJOKA \& MALIK (1997) a produção média de celulase total por Cellulomonas biazotea foi significativamente maior em meios contendo $\alpha$ celulose ou fibras de grama do que nos meios contendo fibra de algodão, Sigmacell-100 e carboximetil celulose, atingindo até $18 \mathrm{UI} / \mathrm{mL} / \mathrm{h}$ a $30^{\circ} \mathrm{C}$.

Após quinze dias de incubação de Pleurotus sajor caju, níveis de atividade de celulase total e $\beta$-glicosidase iguais a $3,7 \mathrm{UI} / \mathrm{g}$ e $0,6 \mathrm{UI} / \mathrm{g}$, respectivamente, foram observados por BISARIA et al. (1997) em palha de arroz.

Bagaço de cana, em cultura mista de Trichoderma reesei LM-UC4 e Aspergillus phoenicis, induziu a produção de celulase total atingindo 13,4 Ul/g, após 120 horas de incubação a $30^{\circ} \mathrm{C}$ (GUTIERREZ-CORREA \& TENGERDY, 1997).

FERNANDES-SALOMÃO et al. (1996) afirmaram que a maioria das enzimas comerciais são obtidas por fermentação submersa, uma vez que os métodos modernos de controle de fermentação são mais facilmente adaptados, os rendimentos são maiores e os custos e riscos de contaminação menores. Por outro lado, DRAETTA \& LOBO FILHO (1980) e NEDER (1992) observaram que a quantidade e propriedades das celulases produzidas por microrganismos dependem das condições de cultivo, sendo que os fatores ambientais influem na produção de celulases e xilanase de diversos fungos.

Avaliou-se, no presente trabalho, a produção de celulases e xilanases de de Aspergillus niger IZ-9, usando bagaço de cana tratado e não-tratado como substrato.

\section{MATERIAL E MÉTODOS}

\subsection{MICRORGANISMO E SUA MANUTENÇÃO}

O microrganismo utilizado foi o fungo filamentoso Aspergillus niger IZ-9, proveniente da Micoteca do Departamento de Agroindústria, Alimentos e 
Nutrição, o qual foi desenvolvido e mantido em meio Czapek-Dox (NEDER, 1992), por aproximadamente sete dias em estufa a $30^{\circ} \mathrm{C}$.

\subsection{MEIO DE CULTURA}

Empregou-se para produção enzimática o meio de cultura de MANDELS \& WEBER (1969) com a seguinte composição: $\mathrm{K}_{2} \mathrm{PO}_{4}(2 \mathrm{~g}),\left(\mathrm{NH}_{4}\right)_{2} \mathrm{SO}_{4}(1,4$ g), $\mathrm{MgSO}_{4} \cdot 7 \mathrm{H}_{2} \mathrm{O}(0,3 \mathrm{~g}), \mathrm{CaCl}(0,3 \mathrm{~g}), \mathrm{FeSO}_{4} .7 \mathrm{H}_{2} \mathrm{O}(5 \mathrm{mg}), \mathrm{MnSO}_{4} \cdot \mathrm{H}_{2} \mathrm{O}$ $(1,56 \mathrm{mg}), \mathrm{ZnSO}_{4} .7 \mathrm{H}_{2} \mathrm{O}(1,4 \mathrm{mg}), \mathrm{CoCl}_{2}(2 \mathrm{mg})$, proteose peptona $(1 \mathrm{~g})$, Tween $80(1 \mathrm{~mL})$ e bagaço de cana $(10 \mathrm{~g})$. $\mathrm{O}$ volume final foi elevado para $1000 \mathrm{~mL}$ com água destilada. Foram utilizados três tipos de bagaço de cana, sem tratamento químico (controle) e tratado com (a) hidróxido de sódio a $4 \%$ e (b) com hidróxido de sódio a $4 \%$, ácido fosfórico e vapor. No tratamento com hidróxido de sódio, $100 \mathrm{~g}$ do bagaço de cana lavado e moído foi tratado com $2000 \mathrm{~mL}$ da solução de hidróxido de sódio a $4 \%$ em autoclave a $121{ }^{\circ} \mathrm{C}$ por 30 minutos. O material recuperado por filtração foi então lavado com água corrente até a neutralidade e seco a $65{ }^{\circ} \mathrm{C}$ até massa constante. No tratamento com hidróxido de sódio, ácido fosfórico e vapor, parte do bagaço obtido do tratamento com $\mathrm{NaOH} 4 \%$, antes das lavagens sucessivas com água corrente, foi neutralizado com ácido fosfórico p.a. e filtrado. O material recuperado foi então seco em estufa a $65{ }^{\circ} \mathrm{C}$ até massa constante. Ao bagaço obtido adicionou-se o mesmo volume de água destilada, autoclavando-o em seguida a $121{ }^{\circ} \mathrm{C}$ por 30 minutos. A suspensão foi filtrada e o material sólido desidratado a $65{ }^{\circ} \mathrm{C}$ até massa constante.

\subsection{PRODUÇÃO DAS ENZIMAS}

Obteve-se suspensão de esporos fúngicos, desenvolvidos em meio Czapek-Dox inclinado, pela adição de $10 \mathrm{~mL}$ água esterilizada. Um mililitro da suspensão foi inoculado em $250 \mathrm{~mL}$ do meio líquido contido em frascos de Erlenmeyer de $500 \mathrm{~mL}$. Os frascos, em triplicata, foram incubados a $30{ }^{\circ} \mathrm{C}$ em agitador rotativo a $100 \mathrm{rpm}$. Amostras foram tomadas diariamente e centrifugadas a $3000 \mathrm{x}$ g, durante 15 minutos, determinandose as atividades enzimáticas no sobrenadante.

\subsection{DETERMINAÇÃO DAS ATIVIDADES ENZIMÁTICAS}

As atividades enzimáticas de celulase total, endoglicanase e $\beta$-glicosidase foram avaliadas segundo metodologias propostas por MANDELS (1974), utilizando-se como substratos papel de filtro, carboximetil celulose e salicina, respectivamente. A atividade de xilanase foi avaliada segundo BAILEY et al. (1992), usando-se xilana Birchwood como substrato. As quantidades de açúcares redutores produzidas, expressas em glicose ou xilose, foram determinadas pelo método do ácido dinitrossalicílico, DNS 
(MILLER, 1959). Uma unidade de atividade enzimática (UI) foi definida como aquela que libera um $\mu \mathrm{mol}$ do açúcar redutor correspondente por minuto a $50{ }^{\circ} \mathrm{C}$.

\subsection{DETERMINAÇÃO DOS TEORES DE CELULOSE E LIGNINA NO BAGAÇO DE CANA}

Os teores de celulose nos bagaços utilizados foram determinados conforme UPDEGRAFF (1969). Bagaço de cana moído foi incubado a $100{ }^{\circ} \mathrm{C}$ com reagente nítrico-acético (ácido acético $80 \%$ e ácido nítrico concentrado) por 30 minutos. Após centrifugação a 3000 x g por 60 minutos, em temperatura ambiente, adicionou-se ao precipitado ácido sulfúrico a $72 \%$. Para determinação do teor celulósico foi adicionado à $1,0 \mathrm{~mL}$ da amostra, $8,0 \mathrm{~mL}$ de solução de antrona a $2 \%$ e $4,0 \mathrm{~mL}$ de água destilada, incubando-se a solução em água fervente por 15 minutos. A leitura espectrofotométrica foi efetuada contra curva padrão de celulose $(\mathrm{mg} / \mathrm{mL})$ a $620 \mathrm{~nm}$.

Os teores de lignina foram determinados de acordo com MILAGRES et al. (1994), sendo considerado como lignina o resíduo sólido restante após as hidrólise com ácido sulfúrico a $72 \%$ e pós-hidrólise com ácido sulfúrico a $4 \%$. O resíduo foi filtrado e lavado, exaustivamente, com água destilada até remoção do ácido excedente, sendo mantido em estufa a $105{ }^{\circ} \mathrm{C}$ até massa constante. $O$ teor de lignina foi expresso pela equação:

$$
\text { LIGNINA }=\frac{\text { massa de lignina }(\mathrm{g})}{\text { massa debagacosec } o} \times 100
$$

\section{RESULTADOS E DISCUSSÃo}

O Aspergillus niger IZ-9 demonstrou capacidade para produzir as frações celulolíticas e xilanase, conforme afirmaram GOKHALE (1986) e BIGELIS (1993). O fungo foi capaz de produzir o complexo celulolítico e xilanase a partir de bagaço de cana, fonte de carbono abundante e barata no Brasil.

$\mathrm{Na}$ Tabela 1 são apresentados os teores de cada fração para os diferentes tratamentos do bagaço de cana-de-açúcar e o controle (sem tratamento).

Com respeito aos teores de celulose, os bagaços tratados foram, em geral, superiores ao bagaço de cana sem tratamento. $\mathrm{O}$ tratamento com $\mathrm{NaOH}$, $\mathrm{H}_{3} \mathrm{PO}_{4}$ e vapor apresentou maior teor de celulose, sugerindo maior extração de frações como a lignina, que representa barreira física aos extratos enzimáticos (Tabela 1). Aparentemente, as diferenças entre os 
resultados obtidos pelos tratamentos são pequenas, porém a vantagem do tratamento com $\mathrm{NaOH}, \mathrm{H}_{3} \mathrm{PO}_{4}$ e vapor está no reduzido tempo de processamento do bagaço. A neutralização com ácido fosfórico foi extremamente rápida em relação ao tratamento com $\mathrm{NaOH}$, no qual a neutralização foi feita com lavagens sucessivas com água. Além do que, tratamentos alcalinos são eficientes e seu custo é reduzido quando comparado à outras técnicas como radiação, ou que requerem equipamentos especiais (steam-explosion). Segundo MENEZES \& HENNIES (1991) o bagaço de cana tratado com soluções alcalinas mostrou-se mais eficiente na síntese das diferentes frações enzimáticas do que o bagaço sem tratamento.

\section{TABELA 1 - TEORES DE CELULOSE E LIGNINA NO BAGAÇO DE CANA}

\begin{tabular}{lcc}
\hline Tipo de bagaço* & \multicolumn{2}{c}{ Frações do bagaço de cana $(\%)$} \\
\cline { 2 - 3 } & celulose & lignina \\
\hline Sem tratamento & 37,0 & 24,6 \\
$\mathrm{NaOH} 4 \%$ & 60,5 & 10,7 \\
$\mathrm{NaOH} 4 \%, \mathrm{H}_{3} \mathrm{PO}_{4}$, vapor & 66,5 & 10,0 \\
\hline
\end{tabular}

*Tipo de bagaço: sem tratamento - bagaço lavado e moído; $\mathrm{NaOH} 4 \%$ - bagaço tratado a $121{ }^{\circ} \mathrm{C}$ com solução de $\mathrm{NaOH}$ a $4 \%$; $\mathrm{NaOH} 4 \%, \mathrm{H}_{3} \mathrm{PO}_{4}$, vapor - bagaço tratado a $121{ }^{\circ} \mathrm{C}$ com solução de $\mathrm{NaOH}$ a $4 \%$ e $\mathrm{H}_{3} \mathrm{PO}_{4}$ p.a. e submetido a tratamento com vapor $\left(121^{\circ} \mathrm{C}\right)$ por 30 minutos.

A Figura 1 mostra os resultados da atividade enzimática de celulase total no extrato bruto, obtido em meios de cultura com os três tipos de bagaços. Verificou-se que produção de celulase total foi maior em bagaço de cana tratado com solução de hidróxido de sódio a $4 \%$ e neutralizado com lavagens sucessivas com água destilada. Atividades de celulase total acima de 0,25 UI. $\mathrm{mL}^{-1}$ e de aproximadamente 0,15 UI. $\mathrm{mL}^{-1}$ foram alcançadas, após 168 horas, com estes bagaços, respectivamente. Possivelmente, o maior teor de lignina no bagaço sem tratamento tenha dificultado a indução da atividade enzimática.

Quanto à produção de endoglicanase, os tratamentos usados não mostraram diferença marcante apesar dos teores de lignina serem diferentes. O bagaço sem tratamento apresentou níveis de produção enzimática para endoglicanase semelhantes aos dos bagaços tratados quimicamente (Figura 2). 
FIGURA 1 - PRODUÇÃo DE CELULASE TOTAL POR Aspergillus niger IZ-9 EM BAGAÇO DE CANA $\left(100 \mathrm{rpm}, 30^{\circ} \mathrm{C}\right)$

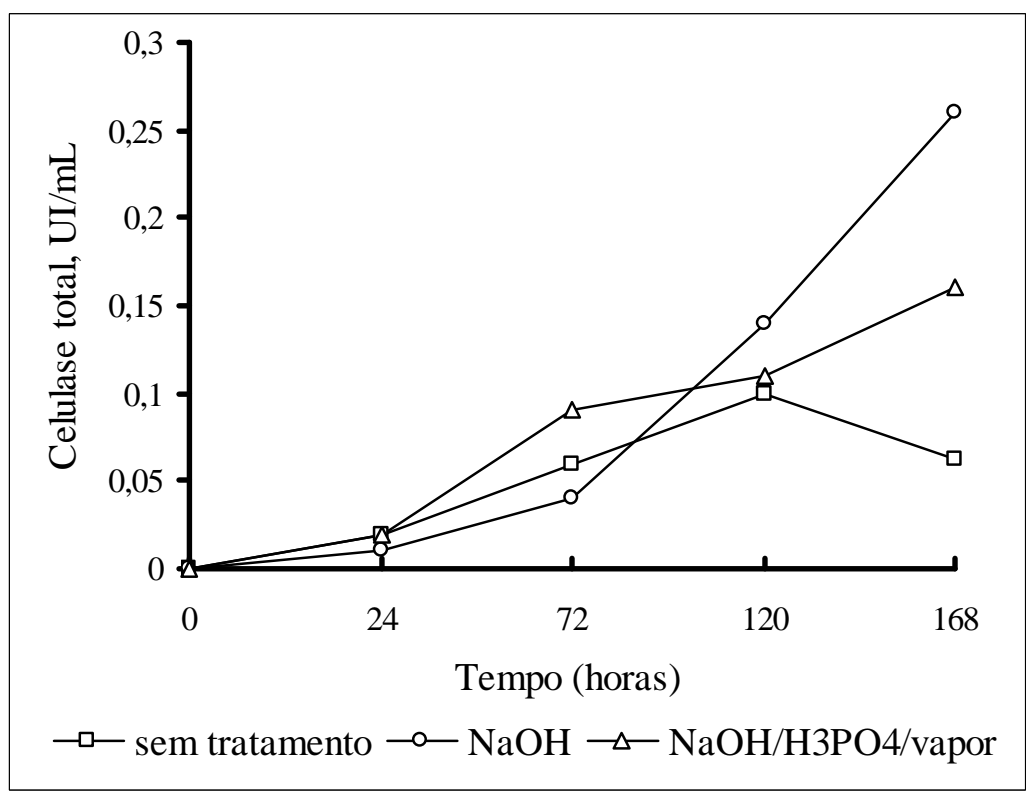

FIGURA 2 - PRODUÇÃO DE ENDOGLICANASE POR Aspergillus niger IZ-9 EM BAGAÇO DE CANA (100 rpm, $\left.30^{\circ} \mathrm{C}\right)$

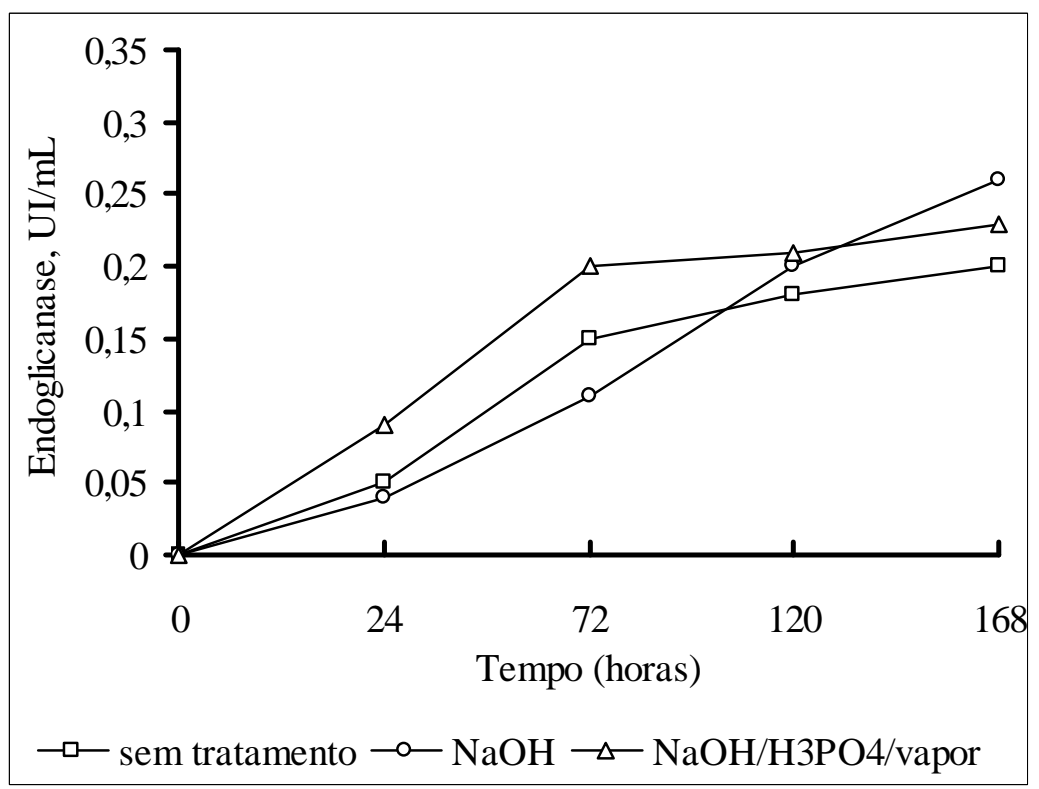


A indução de $\beta$-glicosidase, por outro lado, foi favorecida nos bagaços tratados (Figura 3). Provavelmente, a matriz celulósica estava mais exposta à ação das glicanases, devido ao menor teor de lignina presente nestes bagaços do que no sem tratamento, pois a liberação de celobiose é mais intensa, o que promoveria maior indução de $\beta$-glicosidase.

\section{FIGURA 3 - PRODUÇÃO DE $\beta$-GLICOSIDASE POR Aspergillus niger IZ-9 EM BAGAÇO DE CANA (100 rpm, $\left.30^{\circ} \mathrm{C}\right)$}

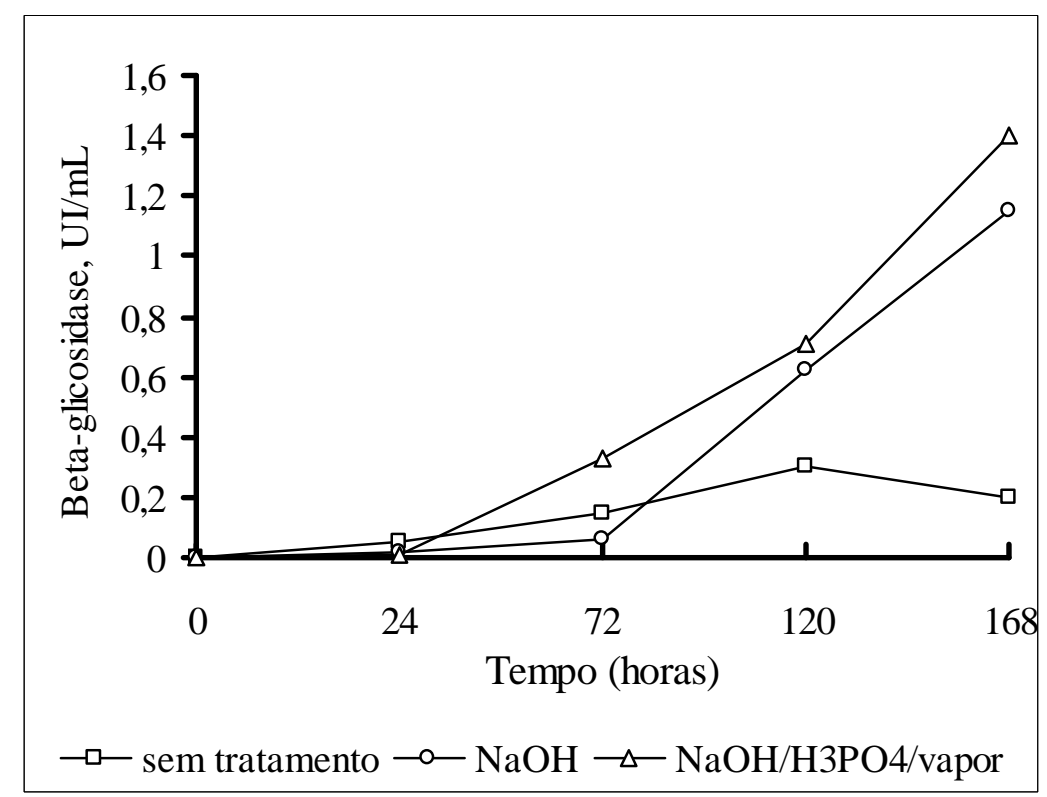

A $\beta$-glicosidase foi melhor induzida pelo bagaço de cana tratado com $\mathrm{NaOH}, \mathrm{H}_{3} \mathrm{PO}_{4}$ e vapor a partir de 72 horas de incubação, embora após 120 horas, as atividades de $\beta$-glicosidase proporcionadas pelos dois substratos tratados tenham sido semelhantes.

De modo geral, houve efeito positivo na indução à síntese das diferentes frações celulolíticas e xilanase propiciada pelos tratamentos alcalinos sobre o bagaço, tanto no uso isolado de hidróxido de sódio quanto associado com ácido fosfórico e vapor (Figura 4). Embora estes tratamentos tenham sido mais eficazes que o bagaço sem tratamento, o efeito foi muito maior em potencializar a $\beta$-glicosidase, cuja atividade foi incrementada cerca de cinco vezes pelo tratamento com $\mathrm{NaOH}, \mathrm{H}_{3} \mathrm{PO}_{4} \mathrm{e}$ vapor, em relação ao bagaço sem tratamento (Figura 3 ). Este fato foi observado por MENEZES \& HENNIES (1991), quando usaram bagaço de cana tratado com peróxido alcalino. 


\section{FIGURA 4 - PRODUÇÃO DE XILANASE POR ASPERGILLUS NIGER IZ- 9 EM BAGAÇO DE CANA $\left(100 \mathrm{rpm}, 30^{\circ} \mathrm{C}\right)$}

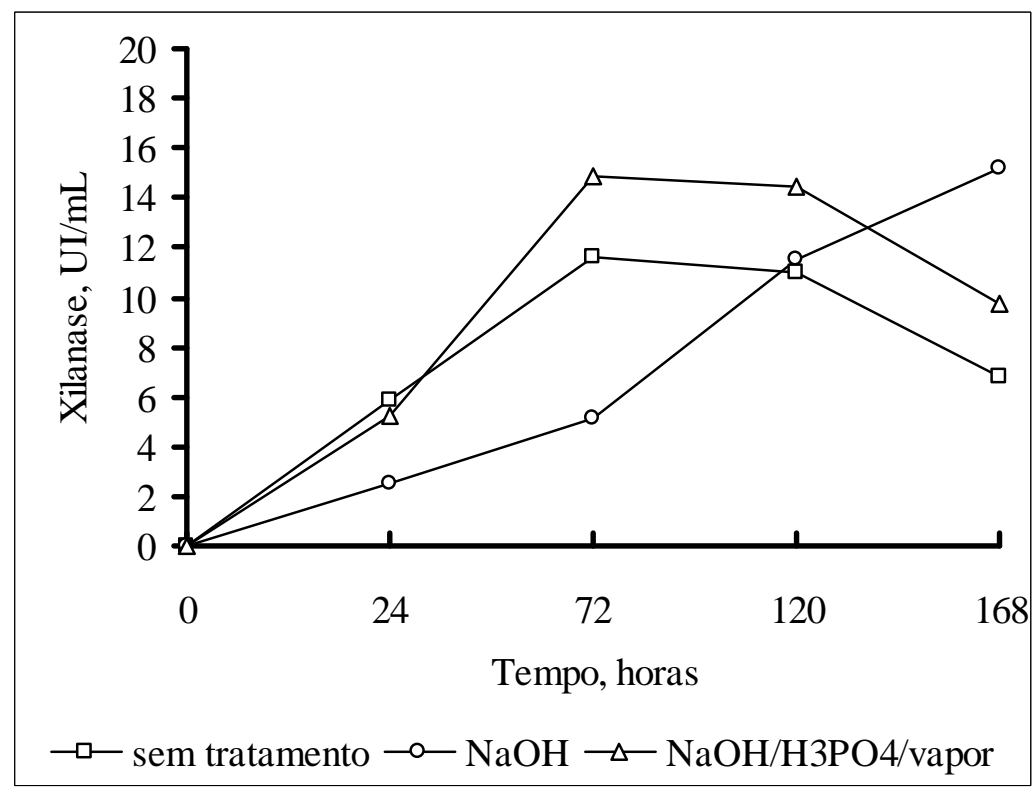

O modo pelo qual o tratamento do substrato aumenta a capacidade de induzir a síntese do complexo celulolítico está relacionado com o aumento da concentração da celulose, indutor de celulases, em função da remoção da lignina. Como constatado neste trabalho, tem sido também demonstrado que tratamentos alcalinos aumentam o teor de celulose pela diminuição do teor de lignina (AGUIAR, 1998; GUPTA \& MADAMWAR, 1997; MENEZES \& HENNIES, 1994; MENEZES \& HENNIES, 1991; MENEZES \& HIOSHII, 1982). A parcial remoção da lignina promoveria a síntese das enzimas pelo microrganismo, por facilitar seu contato com a celulose.

\section{CONCLUSÃO}

O Aspergillus niger IZ-9 pode ser considerado bom produtor de enzimas celulolíticas e hemicelulolíticas, porém torna-se necessário o tratamento alcalino do bagaço de cana para a remoção, pelo menos parcial da lignina presente na fibra vegetal, possibilitando maior indução às sínteses enzimáticas. Dentre os tratamentos estudados, o tratamento com solução de hidróxido de sódio a $4 \%$ promoveu maior indução à síntese da maioria das enzimas, com exceção da $\beta$-glicosidase, que apresentou maior indução com bagaço submetido ao tratamento com solução de hidróxido de sódio, ácido fosfórico e vapor. 


\begin{abstract}
It was evaluated the production of cellulases and xylanase by Aspergillus niger IZ-09 grown in a substrate consisted of chemically treated sugarcane bagasse. The treatments were: $4 \%$ sodium hydroxide solution and $4 \%$ sodium hydroxide solution, phosphoric acid and steam. The production of the cellulolytic enzymes (total cellulase, endoglycanase and $\beta$-glucosidase) and xylanase was observed in the treated and non-treated bagasses. The treatment with $4 \%$ sodium hydroxide solution promoted a greater induction of the synthesis of the majority of the enzymes, with exception of $\beta$-glucosidase, which showed similar production for both chemically treated bagasses.
\end{abstract}

\title{
REFERÊNCIAS BIBLIOGRÁFICAS
}

1 ABD-EL-NASSER, N. H., HELMY, S. M., EL GAMMAL, A. A. Formation of enzymes by biodegradation of agricultural wastes with white rot fungi. Polymer Degradation and Stability, v. 55, n. 7, p. 249-255, 1997.

2 AGUIAR, C. L. Sacarificação de bagaço de cana-de-açúcar (Saccharum spp) usando extrato enzimático. Piracicaba, 1998. p. 77. Dissertação (Mestrado) - Escola Superior de Agricultura "Luiz de Queiroz", Universidade de São Paulo.

3 BAILEY, M. J., BIELY, P., POUTANEN, K. Interlaboratory testing of methods for assay of xylanase activity. Journal of Biotechnology, v. 23, p. 257-270, 1992.

4 BIGELIS, R. Carbohydrases. In: NAGODAWITHANA, T., REED, G. (Ed.). Enzyme in Food Processing. San Diego : Academic Press, 1993. Cap. 6, p. 121-158.

5 BISARIA, R., MADAN, M., VASUDEVAN, P. Utilisation of agroresidues as animal feed through bioconversion. Bioresource Technology, v. 59, n. 1, p. 5-8, 1997.

6 BISARIA, V. S., GHOSE, T. K. Biodegradation of cellulose materials: substrates, microorganisms, enzymes and products. Enzyme Microbiology and Technology, v. 3, p. 90-104, 1984.

7 COSTA, C. J., MEDEIROS, N., SILVA, N. L., LIMA FILHO, J. L., DA SILVA, M. P. C. Utilização de meios nutritivos regionais no cultivo de Aspergillus oryzae, para a produção de amilase, celulase, lipase e protease. In: CONGRESSO NACIONAL DE INICIAÇÃO CIENTÍFICA, 5., 1997. Anais... Recife : UFPE, 1997. 210 p.

8 DA SILVA, R., YIM, D. K., PARK, Y. K. Application of thermostable xylanases from Humicola sp for pulp improvement. Journal Fermentation and Bioengineering, v. 77, p. 109-111, 1994. 
9 DRAETTA, I. S., LOBO FILHO, M. Celulases de basidiomicetos: purificação e caracterização. Coletânea do ITAL, v. 11, p. 163184, 1980.

10 ELISASHVILI, V. L. Biosynthesis and properties of cellulases and xylanases of higher Basidiomycetes. Applied Biotechnology and Microbiology, v. 29, p. 257-266, 1993.

11 FERNANDES-SALOMÃO, T. M., AMORIM, A. C. R., CHAVESALVES, V. M., COELHO, J. L. C., SILVA, D. O., ARAÚJO, E. L. Isolation of pectinase hyperproducing mutants of Penicillium expansum. Revista de Microbiologia, v. 27, p. 15-18, 1996.

12 GOKHALE, D. U. Xylanase and beta-xylosidase production by Aspergillus niger NCIM 1207. Biotechnology Letters, v. 8, p. 137-138, 1986.

13 GONG, C. S., TSAO, G. T. Cellulase and biosynthesis regulation. Annual Reports on Fermentation Process, v. 3, p. 111-139, 1975.

14 GUPTA, A., MADAMWAR, D. Solid state fermentation of lignocellulosic waste for cellulase and beta-glucosidase production by cocultivation of Aspergillus ellipticus and Aspergillus fumigatus. Biotechnology Process, v. 13, n. 4, p. 166-169, 1997.

15 GUTIERREZ-CORREA, M., TENGERDY, R. P. Production of cellulase on sugarcane bagasse by fungal mixed culture solid substrate fermentation. Biotechnology Letters, v. 19, n. 7, p. 665-667, 1997.

16 LATIF, F., RAJOKA, M. I., MALIK, K. A. Production of cellulases by thermophilic fungi grown on Leptochloa straw. World Journal of Microbiology and Biotechnology, v. 11, n. 3, p. 343-348, 1997.

17 LOWE, S. E., THEODOROU, M. K., TRINCI, A. P. J. Cellulases and xylanase of an anaerobic rumen fungus grown on wheat straw holocellulose, cellulose, and xylan. Applied and Environmental Microbiology, v. 53, n. 6, p. 1216-1223, 1987.

18 MANDELS, M. Production and application of cellulase. Massachusetts : Laboratory Procedures, Army Natick Laboratories, 1974. 22 p.

19 MANDELS, M., WEBER, J. The production of cellulases. Advances in Chemistry Series, v. 95, p. 391-414, 1969. 
20 MENEZES, T. J. B. Os fungos na indústria. Boletim da SBCTA, v. 31, n. 2, p. 116-120, 1997.

21 MENEZES, T. J. B., DE LAMO, P. R., ARAKAKI, T. Produção do complexo celulolítico $C_{1}, C_{x}$ por microrganismos. Coletânea do ITAL, v. 7, p. 91-96, 1976.

22 MENEZES, T. J. B., HENNIES, P. T. Influência do pré-tratamento do bagaço de cana-de-açúcar com peróxido alcalino e hidróxido de sódio no sistema celulolítico de $A$. niger. Coletânea do ITAL, v. 21, n. 2, p. 213-219, 1991.

23 MENEZES, T. J. B., HENNIES, P. T. Sistema celulolítico de Aspergillus niger em substrato sólido de bagaço de cana-deaçúcar tratado. Coletânea do ITAL, v. 24, n. 1, p. 75-89, 1994.

24 MENEZES, T. J. B., HIOSHII, S. H. Efeito do tratamento do bagaço de cana na extensão da hidrólise da celulose. Coletânea do ITAL, v. 12, p. 123-135, 1982.

25 MENEZES, T. J. B., MAKINO, Y., GRILLO, R. L. M. Produção de celulase: efeitos do tratamento do bagaço de cana-de-açúcar na produção de celulase. Coletânea do ITAL, v. 21, n. 1, p. 29-44, 1991.

26 MILAGRES, A. M. F., BORGES, L., AGUIAR, C. L. Degomagem de rami para fins têxteis utilizando extratos enzimáticos. Anais do SHEB, n. 4, p. 261-269,1994.

27 MILLER, G. L. Use of dinitrosalicylic acid reagent for determination of reducing sugar. Analytical Chemistry, v. 31, n. 3, p. 426-428, 1959.

28 NEDER, R. N. Microbiologia: manual de laboratório. São Paulo : Nobel, 1992. 138 p.

29 NOVO NORDISK. Celluclast 1,5 L: ficha técnica. [Curitiba],1996. $3 p$.

30 RAJOKA, M. I., MALIK, K. A. Cellulase production by Cellulomonas biazotea cultured in media containing different cellulosic substrates. Bioresource Technology, v. 59, n. 1, p. 21-27, 1997.

31 SILVA, D. M., DILLON, A. J. P. Produção de celulases em fermentação semi-sólida por uma linhagem de Trichoderma sp In: REUNIÃO ANUAL DE GENÉTICA DE MICRORGANISMOS, 15., 1988. Anais... Piracicaba : FEALQ, 1988. p. 54. 
32 STEVENS, B. J. H., PAYNE, J. Cellulase and xylanase production by yeast of the genus Trichosporon. Journal of Genetic Microbiology, v. 100, p. 381-393, 1977.

33 UMIKALSON, M. S., ARIFF, A. B., SHAMSUDDIN, Z. H., TONG, C. C., HASSAN, M. A., KARIN, M. I. A. Production of cellulase by a wsild strain of Chaetomium globosum using delignified oil palm empty-fruit-bunch fibre as substrate. Applied Microbiology and Biotechnology, v. 47, n. 5, p. 590-595, 1997.

34 VITTI, L. S. S. Condições de produção e atividade da celulase do fungo Aspergillus sp e seus mutantes isolados de bagaço de cana. Piracicaba, 1988. 108 p. Dissertação (Mestrado) - Escola Superior de Agricultura "Luiz de Queiroz", Universidade de São Paulo.

35 VLAEV, S. D., DJEJEVA, G., RAYKOVSKA, V., SCHÜGERL, L. Cellulase production by Trichoderma sp grown on corn fibre substrate. Process Biochemistry, v. 32, n. 7, p. 561-565, 1997. 